\title{
MIDDAY DROP OF RELATIVE LEAF WATER CONTENT TO DROUGHT TOLERANCE IN SOYBEAN
}

\author{
J.A. Chowdhury ${ }^{1}$, M.A.Karim ${ }^{2}$, Q. A. Khaliq ${ }^{2}$, M.S.A. Khan ${ }^{1}$, S. K. Paul ${ }^{1}$ and A.U. Ahmed ${ }^{3}$ \\ ${ }^{1}$ Agronomy Division, Bangladesh Agricultural Research Institute, Gazipur-1701 \\ ${ }^{2}$ Department of Agronomy, Bangabandhu Sheikh Mujibur Rahman Agricultural University, Gazipur-1706 \\ ${ }^{3}$ Plant Pathology Division, Bangladesh Agricultural Research Institute, Gazipur-1701 \\ Corresponding author: jasminedaisy.bari@gmail.com
}

Key words: Relative water content, midday drop of RWC, soybean

\begin{abstract}
An experiment was conducted in a Venylhouse of Bangabandhu Sheikh Mujibur Rahman Agricultural University during September to December 2012 to determine the effect of midday drop of relative water content (RWC) on drought tolerance of soybean genotypes. Four soybean genotypes viz. Shohag, BARI Soybean-6, BD2331 and BGM2026 were used in the study. Plants were grown in pots under stress and control condition. A marked difference in RWC between morning and midday was observed both in stressed and control plants. BARI Soybean- 6 showed higher RWC than rest of the genotypes and BGM2026 showed the lowest at all growth stages. The reduced RWC of BARI Soybean- 6 under water stress at vegetative, flowering and pod developing stages were $11.35,13.52$ and $15.04 \%$ at $1.00 \mathrm{PM}$ as compared to control, respectively. The reduced RWC of BGM2026 at vegetative, flowering and pod developing stages were $18.99,20.64$ and $23.05 \%$ at $1.00 \mathrm{PM}$, respectively. In stressed plants, midday drop of relative water content was minimal in BARI Soybean-6 $(8.97 \%)$ and maximum in BGM2026 $(17.89 \%)$ at $1.00 \mathrm{PM}$. Under water stress condition BARI Soybean- 6 gave the highest seed yield (5.23 g plant $\left.^{-1}\right)$ and BGM2026 the lowest (3.21 $\mathrm{g} \mathrm{plant}^{-1}$ ) which might be attributed to the drastic reduction in 100-seed weight of RWC in the variety BGM2026 due to the significant reduction in RWC in this variety. Considering the midday drop of RWC and seed yield, it may be concluded that BGM2026 is susceptible and BARI Soybean-6 is drought tolerant among the genotypes.
\end{abstract}

\section{Introduction}

Soybean is an important grain legume. It plays an important role in supplying protein and oil needed by humans. Water deficit adversely affects many physiological processes related to water use efficiency in soybean, thus leading to a decrease in plant productivity (Hamayun et al., 2010). Water stress has been found to decrease leaf water potential, relative water content and exudation rate and also to influence leaf anatomical characteristics and photosynthetic parameters (Omae et al., 2005; Omae et al., 2007). So, there is a general consensus that water economy is very critical to plant growth and development. The drought stress mainly causes lowering in some agronomic traits of soybean such as pod setting ratio, early pod abscission and finally leads to lower productivity (Suzuki et al., 2001; Tsukaguchi et al., 2003). Among several methods used to characterize internal plant water status under drought conditions, relative water content (RWC) is an integrative indicator (Parsons and Howe, 1984), and was used successfully to identify drought resistance in french bean (Rosales-Serna et al., 2004; and mustard (Mondal and Paul, 1992). Cultivars with a smaller midday drop in leaf water content set more pods than the cultivars showing a larger midday drop in leaf water content (Omae et al., 2004; Omae et al., 2005). During plant development, drought stress significantly reduced RWC values from 88 to 45\% (Siddique et al., 1999). Soybean yield enhancement requires selection of tolerant and compatible cultivar in dry climate and low water environment (Maleki et al., 2013). Therefore, the present experiment was undertaken to determine the effect of midday drop of relative water content (RWC) on drought tolerance of soybean genotypes. 


\section{Materials and methods}

A pot experiment was conducted in a Vinyl house at Bangabandhu Sheikh Mujibur Rahman Agricultural University during September to December 2012. Three relatively water stress tolerant (Shohag, BARI Soybean-6 and BD2331) and one susceptible (BGM2026) genotype selected from the previous experiment were used in this study to determine the effect of midday drop of relative water content (RWC) on drought tolerance of soybean genotypes at vegetative, flowering and pod development stages. Seeds of tolerant genotypes and susceptible genotypes were sown in plastic pots, $30 \mathrm{~cm}$ in height and $24 \mathrm{~cm}$ inner diameter. The soil of the pot was filled with mixture of soil and cowdung at a ratio of $4: 1$. Pot contained $12.0 \mathrm{~kg}$ of soil which was equivalent to $9 \mathrm{~kg}$ oven dry soil with $28 \%$ moisture at field capacity (FC). Soil used in the pot was sandy loam. The soil of the pot was fertilized uniformly with 24-30-60-15 kg NPKS per hectare, respectively. Six seeds pot ${ }^{-1}$ were sown on 3 September, 2012. After seedling establishment two uniform and healthy plants pot $^{-1}$ were allowed to grow. Drought stress (water stress; 50\% water of the FC) and non-stress (control) treatments were applied at 21 days after emergence (DAE) and maintained throughout the growing seasonThe pots were arranged in a completely randomized design (Factorial) with four replications. General management practices were applied for all the treatments equally. Relative water content, midday drop of relative water content, yield contributing characters and yields were recorded. RWC and midday drop of RWC were measured by following methods.

Relative water content (RWC) of leaves was measured at vegetative, flowering and pod development stages of each genotype at 8:00 am and 1:00 pm. Fully developed $3^{\text {rd }}$ leaf from the top was used for RWC measurement. Immediately after cutting, leaves were sealed within plastic bags and kept in ice box and quickly transferred to the laboratory. The fresh weight of leaves from each treatment was recorded just after removal. Turgid weight (TW) was obtained after soaking leaves in distilled water in beakers for 24 hours at room temperature (about $20^{\circ} \mathrm{C}$ ) and under low light condition of the laboratory. After soaking, leaves were quickly and carefully blotted dried with tissue paper in preparation for determining turgid weight. Dry weight (DW) of the leaf was obtained after oven drying the leaf samples for 72 hour at $70^{\circ} \mathrm{C}$. RWC was calculated using the formula of Schonfeld et al. (1988):

$\mathrm{RWC}(\%)=(\mathrm{FW}-\mathrm{DW}) /(\mathrm{TW}-\mathrm{DW}) \times 100$

Where, FW = Fresh weight, DW = Dry weight, $\mathrm{TW}=$ Turgid weight

Midday drop of RWC: The difference of RWC at mid-day (1:00 pm) to that in the morning (8:00 am) was calculated for mid-day drop of RWC. The data were analyzed by MSTAT-C statistical package program and treatments means were compared by Least Significant Difference (LSD) test (Gomez and Gomez, 1983). Functional relationships among different parameters as affected by water stress were established through correlation and regression analyses by using Excel program.

\section{Results and discussion}

\section{Relative water content}

RWC values of four genotypes at three different stages are shown in Figs 1, 2 and 3. Water stress significantly reduced RWC at two sampling times (8:00 AM and 1:00 PM) across the genotypes at different growth stages in all the four soybean genotypes studied. At $8.00 \mathrm{am}, \mathrm{RWC}$ of water stressed plants of Shohag decreased by $9.47,9.99$ and $12.26 \%$, BARI Soybean- 6 decreased by 8.92, 9.96 and $11.78 \%$, BD2331 decreased by $8.79,10.32$ and $13.16 \%$, and BGM2026 decreased by $13.74,14.17$ and $16.04 \%$ from control plants at vegetative, flowering and pod development stages, respectively. At 1.00 PM, RWC of water stressed plants decreased by 11.99, 13.74 and 15.29\% in Shohag, 11.35, 
Midday Drop of Relative Leaf Water Content to Drought Tolerance in Soybean

13.52 and $15.04 \%$ in BARI Soybean-6, 10.8, 14.9 and $16.04 \%$ in BD2331 and 18.99, 20.64 and $23.05 \%$ in BGM2026 at vegetative, flowering and pod development stages, respectively.

Plants grown under water stress conditions showed a lower RWC than those grown under non stress conditions. Relative water content was higher in the morning, while decreased at noon. Several researchers reported that RWC of different crops was the highest in the morning and thereafter gradually decreased (Pual and Aman, 2000; Omae et al., 2005. BARI Soybean-6 had higher RWC than the rest of genotypes whereas genotype BGM2026 had the lowest RWC at all the three growth stages under both non-stress and stress condition. The RWC of all the genotypes fell at noon, possibly due to higher evaporation resulting from increased temperature and light intensity.

\section{Midday drop of relative water content}

The water stress reasonably affected the mid-day drop of RWC (Fig. 1-3). The difference of RWC between watered and water stressed plants was clear in the midday drop of RWC of the genotypes. In both watered and drought-stressed plant it was minimal in BARI Soybean- 6 and the greatest in BGM2026. Irrespective of genotypes, the higher value was recorded in the plants under water stress at all the growth stages.

The midday drops of RWC at non-stressed plants were 4.49, 4.86 and $6.08 \%$ in Shohag, 4.03, 5.06 and $5.47 \%$ in BARI Soybean-6, 4.72, 5.70 and $8.38 \%$ in BD2331 and 5.43, 7.93 and $10.42 \%$ in BGM2026 at vegetative, flowering and pod development stages, respectively. In water stressed plants the midday drops of RWC were 7.10, 8.83 and $9.33 \%$ in Shohag, 6.59, 8.46 and $8.97 \%$ in BARI Soybean-6, 6.82, 8.92 and $11.41 \%$ in BD2331and 11.19, 14.87 and $17.89 \%$ in BGM2026 at vegetative, flowering and pod development stages, respectively.

In well watered plants, the mid-day drop of RWC was minimal in BARI Soybean-6 at vegetative and pod development stage while in Shohag at flowering stage under water-stressed plants, it was minimal in BARI Soybean-6 followed by Shohag and BD2331 irrespective of growth stages. The maximum RWC was recorded in BGM2026 under both the water regimes. Omae et al. (2005) reported that tolerant cultivars had the lowest mid-day drop of RWC as compared to susceptible cultivars. They suggested that mid-day drop of RWC might be used as a screening marker for drought tolerance of Phaseolus vulgaris.

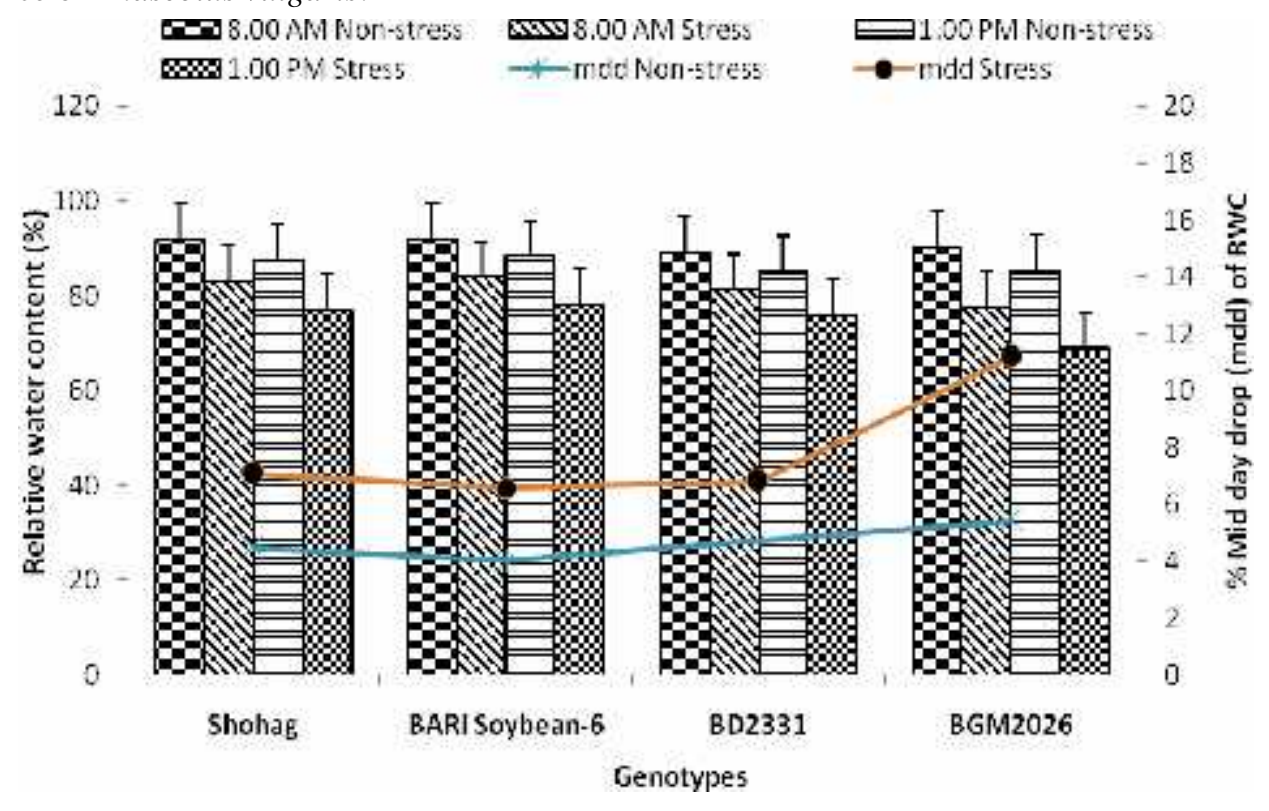


Fig. 1. Relative water content (RWC) and mid-day drop of RWC in soybean genotypes under non-stress and water stress conditions at vegetative stage.

Vertical bar represent LSD value at 5\% level of significant.

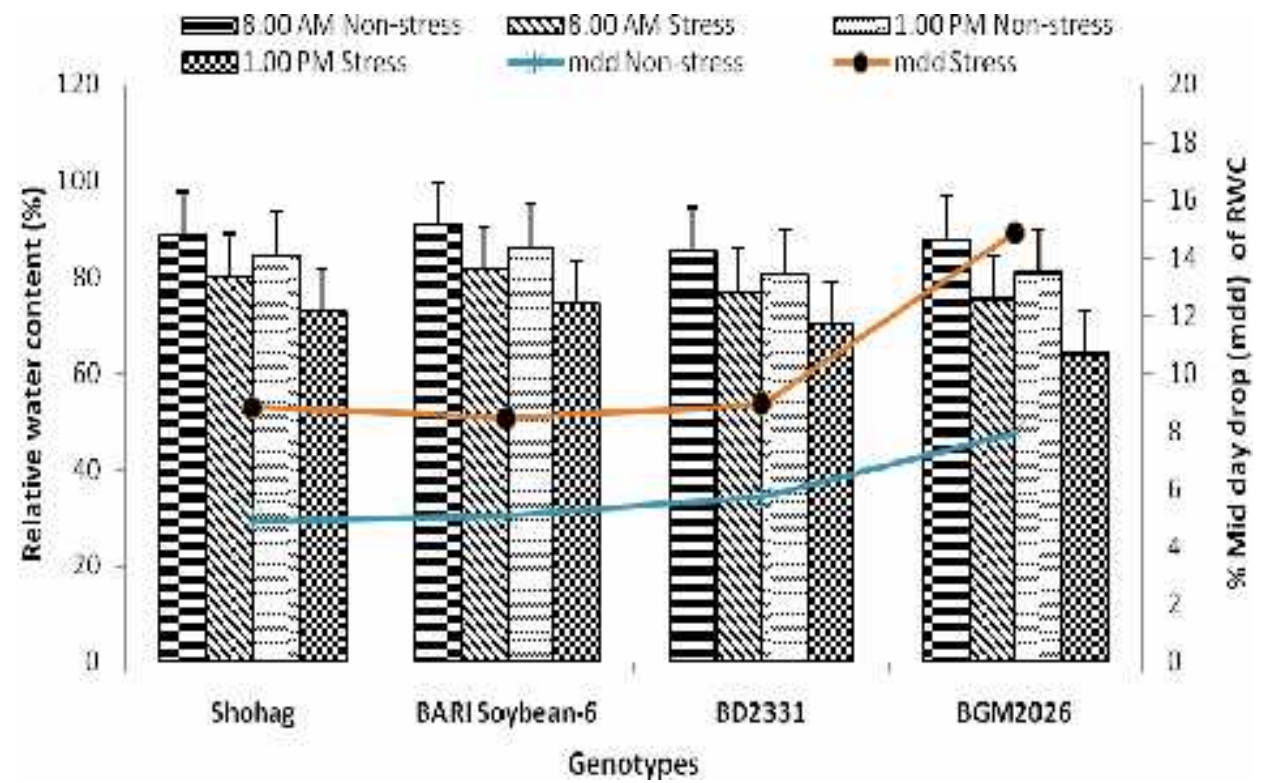

Fig. 2. Relative water content (RWC) and mid-day drop of RWC in soybean genotypes under nonstress and water stress conditions at flowering stage.

Vertical bar represent LSD value at 5\% level of significant.

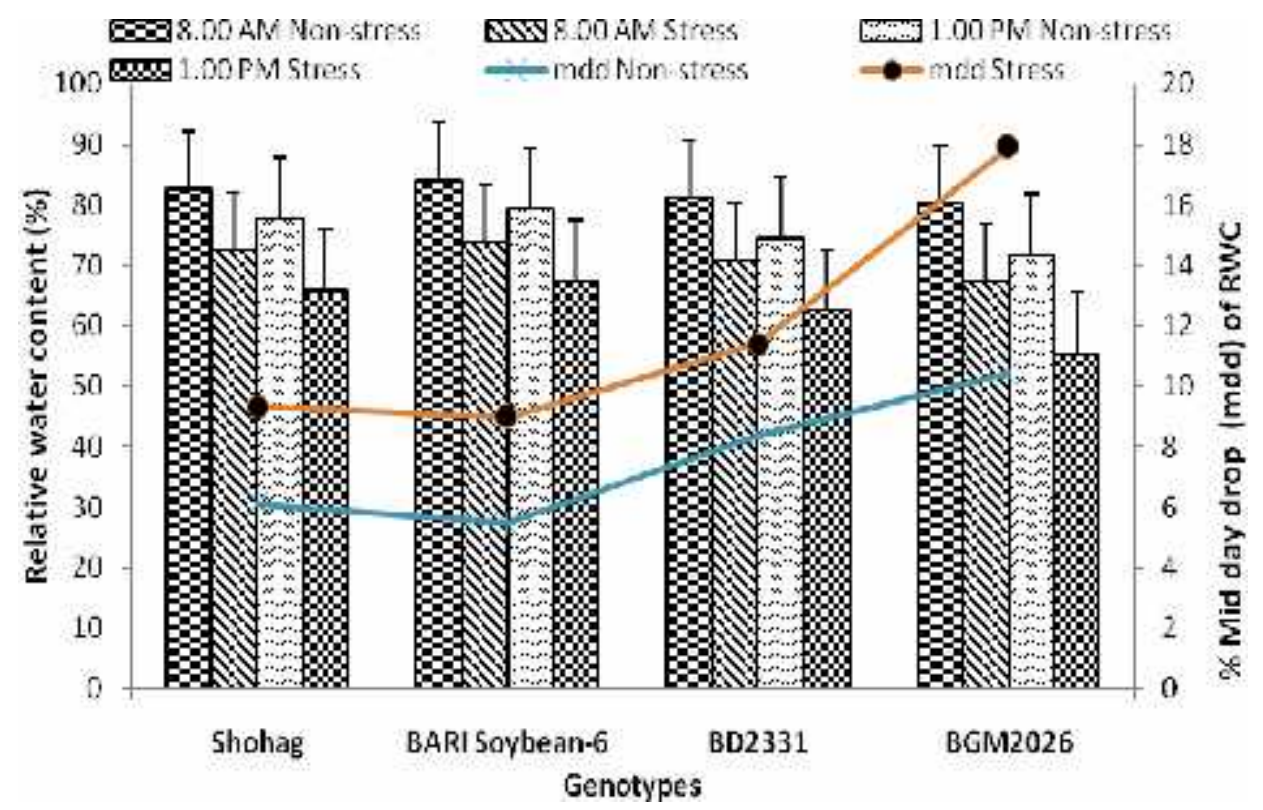

Fig. 3. Relative water content (RWC) and mid-day drop of RWC in soybean genotypes under nonstress and water stress conditions at pod development stage. 
Midday Drop of Relative Leaf Water Content to Drought Tolerance in Soybean

Vertical bar represent LSD value at 5\% level of significant.

\section{Yield components and seed yield}

Moisture levels affected significantly the yield and yield contributing characters of soybean genotypes. Water stress significantly reduced the number of pod plant ${ }^{-1}$ of all the genotypes studied (Table 1). The maximum t pods plant ${ }^{-1}$ was found in BGM2026 (69.18) followed by BARI Soybean-6 (54.41), Shohag (51.85) and the lowest in BD2331 (51.18) under non-stress condition. On the contrary, the number of pods plant ${ }^{-1}$ was the maximum in BARI Soybean-6 (29.37), followed by Shohag (27.92), BD2331 (25.34) and the lowest in BGM2026 (21.34) under water stress situation. The genotype BGM2026 was the most affected genotype by the water stress with $69.51 \%$ reduction of pods plant ${ }^{-1}$; whereas, $46 \%$ in BARI Soybean-6. Shohag and BD2331 showed 46.15 and $50.48 \%$, respectively. Cultivars showing a smaller mid-day drop in leaf water content set more pods than the cultivars showing a large mid-day drop in leaf water content (Omae et al., 2004). Water stress also significantly reduced seeds number pod $^{-1}$ of all the soybean genotypes studied (Table 1). Genotype BGM2026 produced significantly highest seeds number pod $^{-1}$ under non-stress condition and the lowest under stress condition. Shohag produced the highest number of seeds pod $^{-1}$ under stress condition. This character was reduced by water stress in BGM2026 by $19.45 \%$ but in Shohag it was only $5.02 \%$. Hundred seed weight was significantly decreased by the water stress in all the genotypes (Table 2). The highest seed weight was found in BARI Soybean-6 and the lowest in BGM2026 in both the conditions.

Reductions in 100-seed weight ranged from 3.11 to $15.97 \%$ under water stress conditions compared to the non-stressed conditions. The reduction of 100-seed weight was the highest in the genotypes BGM2026 (15.97\%). The result is in consistent with other studies, which indicated that water stress drastically reduced the number of pods plant $^{-1}$ as compared to 100-seed weight (Lizana et al., 2006 and Nunez-Barrios et al., 2005).

Crop yield is mainly a function of various components such as number of pods plant ${ }^{-1}$, number of seeds $\operatorname{pod}^{-1}$ and seed size. Thus, the seed yield was reduced drastically as a consequence of reduced pods plant ${ }^{-1}$, seeds pod ${ }^{-1}$ and 100-seed weight. Seed yield ranged from 8.69 to $10.32 \mathrm{~g} \mathrm{plant}^{-1}$ and 3.21 to $5.23 \mathrm{~g} \mathrm{plant^{-1 }}$ under non-stress and water stress condition (Table 2), respectively. Among the genotypes the highest seed yield was recorded from BARI Soybean-6 and the lowest from BD2331 under non-stress condition. Under water stress condition BARI Soybean-6 gave the highest yield (5.23 g plant ${ }^{-1}$ ) and BGM2026 the lowest (3.21 g plant $\left.{ }^{-1}\right)$. Yield reduction was ranged from 49.32 to $6846 \%$. The highest reduction (68.46\%) in seed yield was observed in BGM2026 and the reduction of Shohag, BARI Soybean-6 and BD2331 showed 50, 49.32 and 50.58\%, respectively.

Table. 1. Pod number plant ${ }^{-1}$ and seed number pod ${ }^{-1}$ of soybean genotypes under non- stress and water stress conditions

\begin{tabular}{|c|c|c|c|c|c|c|c|}
\hline \multirow{2}{*}{\multicolumn{2}{|c|}{ Genotypes }} & \multicolumn{3}{|c|}{ Pod plant $^{-1}$ (no.) } & \multicolumn{3}{|c|}{ Seeds pod ${ }^{-1}$ (no.) } \\
\hline & & $\begin{array}{l}\text { Non- } \\
\text { stress }\end{array}$ & $\begin{array}{l}\text { Water } \\
\text { stress }\end{array}$ & \% Reduction & $\begin{array}{l}\text { Non- } \\
\text { stress }\end{array}$ & $\begin{array}{l}\text { Water } \\
\text { stress }\end{array}$ & \% Reduction \\
\hline Shohag & & 51.85 & 27.92 & 46.15 & 2.09 & 2.08 & 5.02 \\
\hline BARI Sc & pean-6 & 54.41 & 29.37 & 46 & 2.12 & 1.92 & 9.43 \\
\hline BD2331 & & 51.18 & 25.34 & 50.48 & 2.1 & 1.85 & 11.9 \\
\hline BGM20 & & 69.18 & 21.34 & 69.15 & 2.21 & 1.78 & 19.45 \\
\hline $\operatorname{LSD}_{(0.05)}$ & $\mathrm{S}$ & \multicolumn{2}{|c|}{$* *$} & \multicolumn{4}{|c|}{$* *$} \\
\hline & $\mathrm{G}$ & \multicolumn{2}{|c|}{4.73} & & \multicolumn{2}{|c|}{0.05} & \\
\hline & $S \times G$ & \multicolumn{2}{|c|}{6.69} & & \multicolumn{2}{|c|}{0.07} & \\
\hline $\mathrm{CV}(\%)$ & & \multicolumn{2}{|c|}{9.24} & & \multicolumn{2}{|c|}{3.28} & \\
\hline
\end{tabular}

$\mathrm{S}=$ Stress, $\mathrm{G}=$ Genotypes, $* *$ Significant at $1 \%$ level 
Chowdhury et al.

Number of seeds pod $^{-1}$ and weight of 100-seed also played an important role in lowering the seed yield. Reduction in the seed yield by water stress was also reported for soybean (Liu et al., 2003) and Phaseolus vulgaris (Choudhury 2009; Islam et al., 2004; Omae et al., 2005; Lizana et al., 2006).

Table 2. Hundred seed weight and seed yield plant ${ }^{-1}$ of soybean genotypes under non-stress and water stress conditions

\begin{tabular}{|c|c|c|c|c|c|c|}
\hline \multirow[b]{2}{*}{ Genotypes } & \multicolumn{3}{|c|}{ 100-seed weight $(\mathrm{g})$} & \multicolumn{3}{|c|}{ Seed yield plant ${ }^{-1}(\mathrm{~g})$} \\
\hline & Non-stress & $\begin{array}{l}\text { Water } \\
\text { stress }\end{array}$ & $\begin{array}{c}\text { Reduction } \\
(\%)\end{array}$ & $\begin{array}{l}\text { Non- } \\
\text { stress }\end{array}$ & Water stress & $\begin{array}{c}\text { Reduction } \\
(\%)\end{array}$ \\
\hline Shohag & 13.94 & 13.06 & 6.31 & 9.4 & 4.7 & 50 \\
\hline BARI Soybean-6 & 14.13 & 13.69 & 3.11 & 10.32 & 5.23 & 49.32 \\
\hline BD2331 & 13.61 & 12.69 & 6.75 & 8.69 & 4.29 & 50.58 \\
\hline BGM2026 & 7.01 & 5.89 & 15.97 & 10.18 & 3.21 & 68.46 \\
\hline $\operatorname{LSD}_{(0.05)}$ & \multicolumn{2}{|c|}{$*$} & \multicolumn{4}{|c|}{$* *$} \\
\hline $\mathrm{G}$ & \multicolumn{2}{|c|}{0.97} & \multicolumn{4}{|c|}{ NS } \\
\hline $\mathrm{S} \times \mathrm{G}$ & \multicolumn{2}{|c|}{ NS } & \multicolumn{4}{|c|}{ NS } \\
\hline $\mathrm{CV}(\%)$ & \multicolumn{2}{|c|}{6.73} & \multicolumn{4}{|c|}{1.92} \\
\hline
\end{tabular}

$\mathrm{S}=\mathrm{Stress}, \mathrm{G}=\mathrm{Genotypes}, \mathrm{NS}=$ Not significant, *Significant at $5 \%$ level, $* *$ Significant at $1 \%$ level

The mid-day drop of RWC negatively correlated with seed yield plant ${ }^{-1}$ and number of pods plant ${ }^{-1}$ (Figs. 1 and 2). Simple linear regression between midday drop of RWC and seed yield suggested that the genotype with a smaller mid-day drop of RWC produced a larger number of pods plant ${ }^{-1}$ and consequently had higher yield as compared to others.

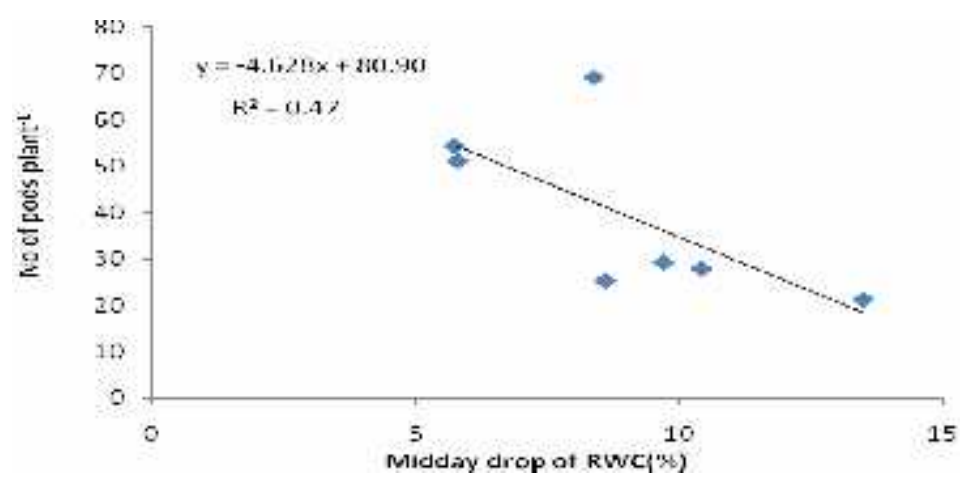

Fig. 1. Functional relationship between mid-day drop of relative water content (RWC) with number of pod plant ${ }^{-1}$ 
Midday Drop of Relative Leaf Water Content to Drought Tolerance in Soybean

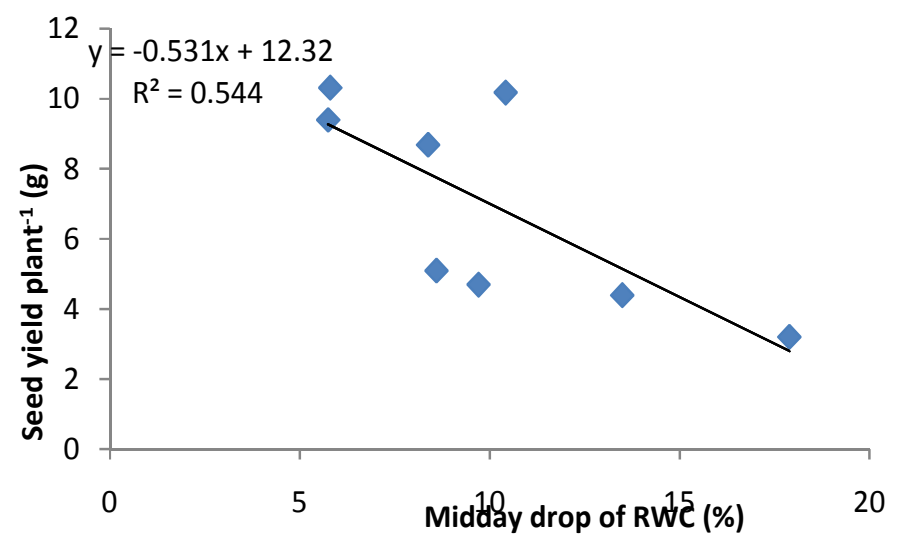

Fig. 2. Functional relationship between mid-day drop of relative water content (RWC) with seed yield plant ${ }^{-1}$

\section{Conclusion}

Considering the midday drop of relative water content, yield contributing characters and seed yield it may be concluded that among the genotypes BARI Soybean-6, Shohag and BD2331 were drought tolerant and BGM26026 was susceptible.

\section{References}

Aguirre, J. F., L. P. J. Ruiz, J. Kohashi-Shibata, C. Trejo-Lopez and J. A. Acosta-Gallegos. 1999. Morphological observations in the leaf surface of Phaseolus vulgaris L. and their possible relationship to stomotal response. Ann. Rep. Bean Improv. Coop. 42: 75-76.

Choudhury, A. K. 2009. Water stress tolerance of french bean (Phaseolus vulgaris L.). Ph. D. Dissertation. Department of Agronomy, Bangabandhu Sheikh Mujibur Rahman Agricultural University, Salna, Gazipur-1706. Bangladesh.

Hamayun M., S. A. Khan, Z. K. Shinwari, A. L. Khan, N. Ahmed, and I. J. Lee. 2010. Effect of poly ethylene glycol induced drought stress on physio-hormonal attributes of soybean. Pak. J. Bot. 42: 977-986.

Iannucci, A., A. Rascio, M. Russo, N. D. Fonzo and P. Martineiello. 2000. Physiological responses to water stress following a conditioning period in berseem clover. Plant Soil 223: 217-227.

Lizana, C., M. Wentworth, J. P. Mart ynez, D. Villegas, R. Meneses, E. H. Murchic, C. Pastenses, B. Lercari, P. Vernieri, P. Horton and M. Pinto. 2006. Differential adaptation of two varieties of common been to abiotic stress. I. Effects of drought on yield and photosynthesis. J. Expt. Bot. 57: 685-697.

Maleki A., A. Naderi, R. Naseri, A. Fathi, S. Bahamin and R. Maleki. 2013. Physiological Performance of Soybean cultivars under drought stress. Bulletin of environment, Pharmacology and life science. 2: $38-44$.

Mondal, R. K. and N. K. Paul. 1992. Effect of irrigation on growth and some physiological characters of mustard (Brassica juncea L.). Bangladesh J. Agric. Res. 17: 29-36.

Nun'ez-Barrios, A., G. Hoogenboom, and D. C. Nesmith. 2005. Drought stress and the distribution of vegetative and reproductive traits of bean cultivar. Sci. Agric. (piracicaba, Braz). 62: 18-22. 
Chowdhury et al.

Omae, H., A. Kumar, Y. Egawa, K. Kashiwaba and M. Shono. 2004. Leaf water status of two snap bean (Phaseolus vulgarid L.) cultivars differing in tolerance to high temperature sress. Jpn. J. Trop. Agric. 48: 5-6.

Omae, H., A. Kumar, K. Kashiwaba and M. Shono. 2007. Assessing drought tolerance of snap bean (Phaseolus vulgaris) from genotypic differences in leaf water relations, shoot growth and photosynthetic parameters. Plant Prod. Sci. 10: 28-35.

Omae, H., A. Kumar, Y. Egawa, K. Kashiwaba and M. Shono. 2005. Midday drop of leaf water content to drought tolerance in snap bean (Phaseolus vulgarid L.). Plant Prod. Sci. 8: 465-467.

Paul, N. K. and R. Aman. 2000. Genotypic variation in physiological characters and grain yield of wheat under low soil moistures. Ann. Bangladesh Agric. 10: 195-201.

Parsons, L. R. and T. K. Howe. 1984. Effects of water stress on the water relatins of Phaseolus vulgaris and the drought resistant Phaseolus acutifolius. Physiol. Plant. 60: 197-202.

Rosales-Serna, R., J. Kohashi-Shibata, J. A. Acosta-Gallegos, C. Trejo-Lopez, J. Ortiz-Cerceres and J. D. Kelly. 2004. Biomas distribution, maturity acceleration and yield in drought-stressed common bean cultivars. Field Crops Res. 85: 203-2011.

Schonfeld, M. A., R. C. Johnson, B. F. Carver, D.W. Mornhinweg. 1988. Water relations in winter wheat as drought resistance indicators. Crop Sci. 28: 526-531.

Siddique, M. R. B., A. Hamid, and M. S. Islam. 1999. Drought stress effects on photosynthetic rate and leaf gas exchange of wheat. Bot. Bull. Acad. Sci. 40: 141-145.

Suzuki, K., T. Tsukaguchi, H. Takeda and Y. Egawa. 2001. Decrease of pollen stainability of snap bean at high temperatures and relationship to heat tolerance. J. Amer. Scos. Hort. Sci. 126: 571-574.

Tsukaguchi, T., Y. Kawamitsu, H. Takeda, K. Suzuki and Y. Egawa. 2003. Water status of flower buds and leaves as affected by temperature in heat-tolerant and heat-sensitive cultivars of snap bean (Phaseolus vulgaris L.). Plant Prod. Sci. 6: 24-27. 